\title{
Pre- and perioperative factors affecting infection after living donor liver transplantation.
}

\section{$\operatorname{AUTHOR}(\mathrm{S}):$}

Kaido, Toshimi; Mori, Akira; Ogura, Yasuhiro; Ogawa, Kouhei; Hata, Koichiro; Yoshizawa, Atsushi; Yagi, Shintaro; Uemoto, Shinji

\section{CITATION:}

Kaido, Toshimi ...[et al]. Pre- and perioperative factors affecting infection after living donor liver transplantation.. Nutrition 2012, 28(11-12): 1104-1108

\section{ISSUE DATE:}

2012-11

URL:

http://hdl.handle.net/2433/160282

\section{RIGHT:}

(c) 2012 Elsevier Inc.; この論文は出版社版でありません。引用の際には 出版社版をご確認ご利用ください。; This is not the published version. Please cite only the published version. 
1 Pre- and perioperative factors affecting infection after living

\section{donor liver transplantation}

Risk factors affecting infection after liver transplantation

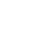

Toshimi Kaido M.D, Akira Mori M.D., Yasuhiro Ogura M.D., Kouhei

Ogawa M.D., Koichiro Hata M.D., Atsushi Yoshizawa M.D., Shintaro Yagi M.D., Shinji Uemoto M.D.

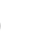

Division of Hepato-Biliary-Pancreatic and Transplant Surgery, Department of Surgery, Graduate School of Medicine, Kyoto University, Kyoto, Japan

4 Authorship: TK, a corresponding author, designed the study, performed 5 the study, collected the data, analyzed the data and wrote the manuscript. $6 \mathrm{AM}, \mathrm{YO}, \mathrm{KO}, \mathrm{KH}, \mathrm{AY}$, and $\mathrm{SU}$ performed the study.

8 Word count: 2703 words including tables, figures and references. Six tables and no figure. 
7

8 Acknowledgments: None of the authors have any conflicts of interest to 9 declare.
Address correspondence to: Toshimi Kaido, M.D. Division of Hepato-Biliary-Pancreatic and Transplant Surgery Department of Surgery, Graduate School of Medicine, Kyoto University 54 Kawahara-cho, Shogoin, Sakyo-ku, Kyoto 606-8507, Japan Tel \& FAX: +81-75-751-4322. E-mail: kaido@kuhp.kyoto-u.ac.jp 


\section{$1 \quad$ Abstract}

2 Objective: Infectious complications including sepsis that often occur after

3 liver transplantation (LT) comprise the most frequent causes of in-hospital

4 death. This study investigated predictors of posttransplant infectious

5 complications to establish a strategy with which to improve short-term

6 outcomes after LT.

7 Methods: We used univariate and multivariate analyses to assess pre- and

8 perioperative risk factors for posttransplant infectious complications among

9100 consecutive patients who underwent living donor LT between February

102008 and February 2010 at our institute.

11 Results: Multivariate analysis showed that low preoperative body cell mass

12 (BCM) and of the absence of preoperative supplementation with

13 branched-chain amino acids were of prognostic significance for

14 posttransplant sepsis. In addition, Child-Pugh classification $\mathrm{C}$ and massive

15 operative blood loss were independent risk factors for posttransplant

16 bacteremia and preoperative low BCM was an independent risk factor for

17 in-hospital death due to infection.

18 Conclusion: Pretransplant nutritional intervention as well as a reduction in

19 operative blood loss would help to prevent posttransplant infectious

20 complications developing during living donor LT. BCAA supplementation

21 before LT affects the occurrence of infectious complications. 
1 Keywords: liver transplantation, infection, nutrition, body cell mass,

2 branched-chain amino acids.

3 


\section{Introduction}

2 Infections after liver transplantation (LT) are the most frequent causes of

3 morbidity and in-hospital death [1]. Patients who undergo LT are

4 essentially regarded as being at unusually high risk for perioperative

5 infection. For example, protein-energy malnutrition, which is common in

6 patients with end-stage liver disease requiring LT, is considered to confer

7 vulnerability to preoperative infection including spontaneous bacterial

8 peritonitis and pneumonia via deteriorated immune function [2,3]. Liver

9 transplantation itself is a massive invasion of the host. The number of

10 intraoperatively transfused cellular blood products is also a risk factor for

11 infections [4]. Furthermore, immunosuppression as well as multiple

12 catheter insertion increases the risk of posttransplant infection.

13 Consequently, infectious complications including sepsis and bacteremia

14 often occur after LT and are the most frequent causes of in-hospital death.

15 Therefore, the prevention of posttransplant infection plays a crucial role in

16 improving short-term outcomes after LT.

17 Malnutrition is a risk factor for postoperative complications and mortality

18 rates in patients with a cirrhotic liver who undergo surgery [5,6]. However,

19 the impact of preoperative nutritional status as well as of nutritional

20 intervention on postoperative infectious complications in LT remains

21 controversial [7-10], especially in patients undergoing living donor LT

22 (LDLT). Patients with advanced cirrhosis characteristically show a decrease 
1 in plasma concentrations of branched-chain amino acids (BCAAs). These

2 BCAAs serve not only as an essential substrate in the synthesis of body

3 proteins, but also act as an important regulator of protein turnover.

4 Moreover, BCAAs have beneficial effects on hepatic encephalopathy

5 through the promotion of ammonia detoxification and the correction of

6 plasma amino acid imbalance, liver regeneration, and hepatic cachexia in

7 patients with liver diseases [11]. Improving systemic conditions, including

8 nutritional status, to the greatest extent possible before LT facilitates early

9 postoperative recovery. Supplementation with a BCAA-enriched nutrient

10 mixture is reportedly beneficial not only for patients with liver cirrhosis,

11 but also for patients undergoing hepatectomy [12-15]. However, the value

12 of pretransplant BCAA supplementation remains unclear. The aim of the

13 present study was therefore to examine pre- and perioperative predictors

14 including nutritional factors such as BCAA supplementation for

15 posttransplant infectious complications so that a strategy can be established

16 to improve short-term outcomes after LDLT.

\section{Methods}

19 The present report retrospectively analyzed data from 100 consecutive

20 adult patients (46 males and 54 females) aged $\geq 18$ (range, $18-69$; median,

21 56) years who underwent LDLT at Kyoto University Hospital between

22 February 2008 and February 2010 after introducing the nutritional 
1 assessment described below. The Model for End-stage Liver Disease

2 (MELD) score was 19 (range, 7 - 46), 32 patients were ABO incompatible

3 and 68 were identical or compatible. The indications for LT were

4 hepatocellular carcinoma $(\mathrm{n}=33)$, followed by hepatocellular diseases

5 such as hepatitis B or C virus-associated liver cirrhosis $(\mathrm{n}=19)$,

6 progressive intrahepatic cholestatic diseases including primary biliary

7 cirrhosis and primary sclerosing cholangitis $(n=13)$, fulminant hepatic

8 failure $(n=11)$ and other causes $(n=24)$. The patients provided written

9 informed consent before the start of the study, which was approved by the

10 Ethics Committee of Kyoto University and conducted in accordance with

11 the Declaration of Helsinki of 1975 as revised in 1996.

12 We introduced body composition analysis using multifrequency

13 bioelectrical impedance with eight tactile electrodes (InBody 720; Biospace,

14 Tokyo, Japan) in February 2008 for patients undergoing LT. Patients fast

15 for at least 3 hours and void immediately before starting the analysis.

16 Various parameters are automatically measured, including body mass index,

17 intra- and extracellular water, body fat mass, protein, and body cell mass

18 (BCM), which is the sum of intracellular fluid and protein and a reliable

19 parameter of nutritional status. The BCM is automatically calculated by the

20 InBody 720 for each patient and displayed as a normal range (e.g. 23.0

$2128.1 \mathrm{~kg}$ ). Low and high BCM values are below the lower limit and above

22 the upper limit, respectively. Ten patients who could not undergo 
1 preoperative InBody 720 examination due to undergoing emergency

2 surgery were excluded from the BCM analysis.

3 Preoperative nutritional therapy was administered for about 2 weeks

4 before LDLT at the discretion of the surgeon or attending physician after

5 admission to our department. The therapy consisted of a nutrient mixture

6 enriched with branched-chain amino acids (BCAA; Aminoleban EN;

7 Otsuka Pharmaceutical Co., Tokyo, Japan), BCAA nutrients (Livact;

8 Ajinomoto Pharma Co., Tokyo, Japan) or none. Thirty-seven of the patients

9 received the preoperative BCAA-enriched nutrient mixture (100 g/day), 28

10 received BCAA nutrients (12.45 g/day), and 35 received no nutritional

11 therapy. Dieticians adjusted the type and amount of food for each patient to

12 maintain a total caloric intake of $35-40 \mathrm{kcal} / \mathrm{kg}$ and a protein intake of 1.2

13 to $1.5 \mathrm{~g} / \mathrm{kg}$ including BCAA nutrients according to the guidelines of the

14 European Society of Parenteral and Enteral Nutrition.

15 The selection criteria for the recipients as well as surgical techniques for 16 recipient operations have been described in detail elsewhere [16-18].

17 Immunosuppressive therapy usually consisted of tacrolimus or

18 cyclosporine and low-dose steroids as described elsewhere $[18,19]$.

19 We examined preoperative risk factors (including preoperative

20 nutritional parameters) for posttransplant sepsis, posttransplant bacteremia

21 and in-hospital death due to infection. Data regarding the following 22 recipient variables for each patient were analyzed: age of recipient, gender, 
1 original disease underlying the need for LT, ABO compatibility, Child-Pugh

2 classification, MELD score, graft type (right or left lobe), graft-recipient

3 weight ratio (GRWR), operative duration, operative blood loss,

4 pretransplant $\mathrm{BCM}$, and preoperative nutritional therapy. We defined

5 conditions fulfilling the diagnostic criteria for systemic inflammatory

6 response syndrome with infections including blood, urine and pulmonary

7 infection as sepsis [20]. Infections were defined using the criteria proposed

8 by the Centers for Disease Control and based on reports regarding liver

9 transplant patients [21]. Isolation of bacteria other than common skin

10 contaminants from a single blood culture in the presence of clinical

11 symptoms or of infection was considered bacteremia. When caused by

12 common skin contaminants, bacteremia was considered significant only if

13 an organism was isolated from two blood cultures and clinical signs of 14 infection were evident.

16 Statistical analysis

17 Categorical variables were compared using the $\chi^{2}$ test or Fisher's exact test

18 where appropriate. Any variable identified as significant $(\mathrm{P}<0.05)$ or with

$19 \mathrm{P}<0.10$ in univariate analyses using the above tests was considered a 20 candidate for multivariate analysis using multiple logistic regression 21 models. A $P$ value of $<0.05$ was considered significant. All data were 22 statistically analyzed using JMP 5.0.1 software. 
2 Results

\section{Posttransplant sepsis}

4 Univariate analysis showed that age $<60$ years, MELD score $\geq 20$, low

5 pretransplant BCM and the absence of preoperative supplementation with

6 the BCAA-enriched nutrient mixture were of prognostic significance for

7 posttransplant sepsis (Table 1). Multivariate analysis revealed that low

8 pretransplant $\mathrm{BCM}(\mathrm{p}=0.032)$ and no preoperative BCAA-enriched

9 nutrient supplementation $(\mathrm{p}=0.020)$ were of independent prognostic

10 significance for posttransplant sepsis (Table 2).

\section{Bacteremia}

13 Age <60 years, Child-Pugh classification C, perioperative blood loss $\geq 10 \mathrm{~L}$ 14 and no preoperative BCAA-enriched supplementation were risk factors for 15 bacteremia (Table 3). Multivariate analysis revealed that Child-Pugh 16 classification $C(p=0.002)$ and perioperative blood loss $\geq 10$ L $(p=0.018)$

17 were independent risk factors for posttransplant bacteremia (Table 4).

19 In-hospital death due to infection

20 Age $<60$ years, Child-Pugh classification $\mathrm{C}$ and low preoperative BCM 21 were significant risk factors for in-hospital death due to infection (Table 5). 
1 Multivariate analysis showed that only low preoperative BCM $(\mathrm{p}=0.004)$

2 was an independent risk factor (Table 6).

4 Discussion

5 The present study examined risk factors affecting three types of infectious

6 complications after LDLT. We identified the independent risk factors as

7 Child-Pugh classification C, massive perioperative blood loss, low

8 pretransplant $\mathrm{BCM}$ and the absence of preoperative supplementation with a

9 BCAA-enriched nutrient mixture. Decompensated liver cirrhosis indicated

10 by Child-Pugh classification $\mathrm{C}$ is usually accompanied by deteriorated

11 immune function and nutritional status at the time of LT. Child-Pugh

12 classification $\mathrm{C}$ was thus undoubtedly a risk factor of postoperative

13 infection, which is in line with the results of our recent report [22]. Massive

14 perioperative bleeding is an established factor for postoperative

15 complications of digestive surgery as well as LT and massive blood loss is

16 usually associated with massive blood transfusion. Homologous blood

17 transfusion has adverse effects such as a risk of infection and

18 graft-versus-host disease. This detrimental effect is supposed to be caused

19 by nonspecific immunosuppression such as decreased CD4/CD8 ratios

$20[23,24]$ and natural killer cell activity $[25,26]$. We recently reported that

21 low pretransplant BCM and the absence of preoperative BCAA-enriched

22 supplementation are closely associated with postoperative sepsis [27]. The 
1 present findings supported not only our previous results but also

2 demonstrated the powerful impact of pretransplant nutritional conditions

3 and preoperative treatment with BCAA-enriched nutrient mixture on

4 infectious complications.

5 The reason for the beneficial effects of pretransplant BCAA

6 supplementation, however, remains unclear. One possible explanation is

7 improvement in pretransplant nutritional status. Some nutritional

8 parameters, such as prealbumin, total lymphocyte count, and

9 BCAA/tyrosine ratio, were significantly improved by pretransplant

10 nutritional intervention including BCAA-enriched nutrient mixture (in

11 submission). Another possible reason is the improvement of the immune

12 system. Bassit et al. reported that BCAA supplementation improves the

13 ability of peripheral blood mononuclear cells to proliferate in response to

14 mitogens after long distance intense exercise [28]. Lorenzo et al. reported

15 that septic patients receiving a high-BCAA preparation showed decreased

16 mortality and improved nutritional parameters [29]. In patients with

17 advanced liver cirrhosis, Kakazu et al. showed that elevating extracellular

18 concentration of BCAAs ex vivo improved the function of myeloid

19 dendritic cells [30]. Our results suggest that preoperative BCAA-enriched

20 supplementation can help to prevent postoperative sepsis through

21 nutritional and immune improvement, although a randomized controlled

22 study is required to confirm this hypothesis. Taken together with our 
1 findings demonstrating that the absence of posttransplant enteral nutrition

2 is a risk factor affecting in-hospital mortality after LT [1], perioperative

3 nutritional treatment represents a promising strategy for improving

4 short-term outcomes after LT.

5 Based on the current findings, we considered establishing an

6 interventional strategy against these risk factors to prevent posttransplant

7 infectious complications. Child-Pugh classification $\mathrm{C}$ itself is an indication

8 for LT. In contrast, massive blood loss, pretransplant low BCM and the

9 absence of preoperative BCAA-enriched supplementation are factors that

10 can be altered to some extent. Blood loss can be reduced by more careful

11 surgical maneuvering and the frequent application of hemostatic devices

12 during dissection of the liver from surrounding ligaments and the inferior

13 vena cava. The sum of intracellular fluid and body protein, BCM, is

14 considered a highly reliable parameter of nutritional status. Especially for

15 patients undergoing LT who usually have abundant extracellular fluid such

16 as edema and ascites, $\mathrm{BCM}$ can assess their nutritional status more

17 accurately than other nutritional parameters including body mass index and

18 lean body mass. Low BCM in patients with cirrhosis suggests a decrease in

19 skeletal muscle volume, which could interfere with early postoperative

20 mobilization and result in pulmonary complications including aspiration

21 pneumonia and atelectasis. Therefore, we have recently introduced a

22 pretransplant rehabilitation program to encourage early postoperative 
1 mobilization and avert pulmonary dysfunction. Since LDLT is an elective

2 procedure that differs from deceased donor LT, a pretransplant

3 rehabilitation program can be implemented until the day of transplant.

4 The prevalence of metabolic disorders including metabolic syndrome

5 on liver-transplant population has recently attracted attention [31-33].

6 The prevalence of metabolic syndrome in post-LT patients is

7 significantly higher than that estimated in the general population and

8 metabolic syndrome is associated with an increased risk of major

9 vascular events and long-term fibrosis progression. Therefore,

10 prevention of post-LT metabolic syndrome would also be a crucial

11 objective of perioperative nutritional treatment.

12 Supplementation with a BCAA-enriched nutrient mixture is reportedly

13 beneficial not only for patients with liver cirrhosis but also for patients

14 undergoing hepatectomy [23-26]. However, the value of pretransplant

15 BCAA supplementation has remained unclear. Our results suggest that

16 preoperative BCAA-enriched supplementation can help to prevent

17 postoperative sepsis, although a randomized controlled study is required to

18 confirm this notion. Taken together with our findings demonstrating that

19 the absence of posttransplant enteral nutrition is a risk factor affecting

20 in-hospital mortality after LT [1], perioperative nutritional treatment should

21 be a promising strategy to improve short-term outcomes after LT. 


\section{Conclusion}

2 Preoperative nutritional status, supplementation with a nutrient mixture

3 enriched with BCAAs and massive operative blood loss were closely

4 associated with the occurrence of posttransplant infectious complications.

5 Perioperative management including nutritional therapy is needed to

6 improve short-term outcomes after LT.

7

8 


\section{$1 \quad$ References}

2 1. Kaido T, Egawa H, Tsuji H, Ashihara E, Maekawa T, Uemoto S.

3 In-hospital mortality in adult recipients of living donor liver

4 transplantation: experience of 576 consecutive cases at a single center.

$5 \quad$ Liver Transpl 2009;15:1420-5.

6 2. Pikul J, Sharpe MD, Lowndes R, Ghent CN. Degree of preoperative

7 malnutrition is predictive of postoperative morbidity in liver transplant

$8 \quad$ recipients. Transplantation 1994;57:469-72.

9 3. Stickel F, Inderbitzin D, Candinas D. Role of nutrition in liver 10 transplantation for end-stage chronic liver disease. Nutr Rev $11 \quad 2008 ; 66: 47-54$.

12 4. Palomo Sanchez JC, Jimenez C, Moreno Gonzalez E, Garcia I, Palma F,

13 Loinaz $\mathrm{C}$, et al. Effects of intraoperative blood transfusion on

14 postoperative complications and survival after orthotopic liver

15 transplantation. Hepatogastroenterology 1998;45:1026-33.

16 5. Merli M, Nicolini G, Angeloni S, Riggio O. Malnutrition is a risk factor

17 in cirrhotic patients undergoing surgery. Nutrition 2002;18:978-86.

18 6. Millwala F, Nguyen GC, Thuluvath PJ. Outcomes of patients with 19 cirrhosis undergoing non-hepatic surgery: risk assessment and 20 management. World J Gastroenterol 2007;13:4056-63. 
1 7. Stephenson GR, Moretti EW, El-Moalem H, Clavien PA, Tuttle-Newhall

2 JE. Malnutrition in liver transplant patients: preoperative subjective

3 global assessment is predictive of outcome after liver transplantation.

$4 \quad$ Transplantation 2001;72:666-70.

5 8. Harrison J, McKiernan J, Neuberger JM. A prospective study on the

6 effect of recipient nutritional status on outcome in liver transplantation.

$7 \quad$ Transpl Int 1997;10:369-74.

8 9. Shahid M, Johnson J, Nightingale P, Neuberger J. Nutritional markers in

9 liver allograft recipients. Transplantation 2005;79:359-62.

10 10. de Luis DA, Izaola O, Velicia MC, Sánchez Antolín G, García Pajares

$11 \mathrm{~F}$, Terroba MC, et al. Impact of dietary intake and nutritional status on

12 outcomes after liver transplantation. Rev Esp Enferm Dig 2006;98:6-13.

13 11. Holecek, M. Three targets of branched-chain amino acid 14 supplementation in the treatment of liver disease. Nutrition $15 \quad 2010 ; 26: 482-90$.

16 12. Marchesini G, Bianchi G, Merli M, Amodio P, Panella C, Loguercio C,

17 et al. Italian BCAA Study Group: Nutritional supplementation with 18 branched-chain amino acids in advanced cirrhosis: a double-blind, 19 randomized trial. Gastroenterology 2003;124:1792-801.

20 13. Meng WC, Leung KL, Ho RL, Leung TW, Lau WY. Prospective 21 randomized control study on the effect of branched-chain amino acids in 
1 patients with liver resection for hepatocellular carcinoma. Aust N Z J

$2 \quad$ Surg 1999;69:811-5.

3 14. Fan ST, Lo CM, Lai EC, Chu KM, Liu CL, Wong J. Perioperative

4 nutritional support in patients undergoing hepatectomy for hepatocellular

$5 \quad$ carcinoma. N Engl J Med 1994; 331:1547-52.

6 15. Kawamura E, Habu D, Morikawa H, Enomoto M, Kawabe J, Tamori A,

7 et al. A randomized pilot trial of oral branched-chain amino acids in

8 early cirrhosis: validation using prognostic markers for pre-liver

$9 \quad$ transplant status. Liver Transpl 2009;15:790-7.

10 16. Inomata Y, Uemoto S, Asonuma K, Egawa H. Right lobe graft in living

11 donor liver transplantation. Transplantation 2000;69:258-64.

12 17. Ito $\mathrm{T}$, Kiuchi $\mathrm{T}$, Egawa $\mathrm{H}$, Kaihara $\mathrm{S}$, Oike $\mathrm{F}$, Ogura $\mathrm{Y}$, et al.

13 Surgery-related morbidity in living donors of right-lobe liver graft:

14 lessons from the first 200 cases. Transplantation 2003;76:158-63.

15 18. Morioka D, Egawa H, Kasahara M, Ito T, Haga H, Takada Y, et al.

16 Outcomes of adult-to-adult living donor liver transplantation: a single

17 institution's experience with 335 consecutive cases. Ann Surg $18 \quad 2007 ; 245: 315-25$.

19 19. Inomata Y, Tanaka K, Egawa H, Uemoto S, Ozaki N, Okajima H, et al.

20 The evolution of immunosuppression with FK 506 in pediatric living 21 related liver transplantation. Transplantation 1996;61:247-52. 
1 20. American College of Chest Physicians/Society of Critical Care

2 Medicine Consensus Conference Committee: Definitions for sepsis and

3 organ failure and guidelines for the use of innovative therapies in sepsis.

$4 \quad$ Crit Care Med 1992;20:864-74.

5 21. Garner J, Jarvis W, Emori T, Horan T, Hughes J. CDC definitions for

6 nosocomial infections, 1988. Am J Infect Control 1988;16:128-40.

7 22. Iida T, Kaido T, Yagi S, Yoshizawa A, Hata K, Mizumoto M, et al.

8 Posttransplant bacteremia in adult living donor liver transplant recipients.

$9 \quad$ Liver Transpl 2010;16:1379-85.

10 23. Kaplan J, Sarnaik S, Gitlin J, Lusher J. Diminished helper/suppressor

11 lymphocyte ratios and natural killer activity in recipients of repeated

12 blood transfusions. Blood 1984;64:308-10.

13 24. Kwon AH, Matsui Y, Kamiyama Y. Perioperative blood transfusion in

14 hepatocellular carcinomas: influence of immunologic profile and 15 recurrence free survival. Cancer 2001;91:771-8.

16 25. Tartter PI, Steinberg B, Barron DM, Martinelli G. The prognostic

17 significance of natural killer cytotoxicity in patients with colorectal 18 cancer. Arch Surg 1987;122:1264-68.

19 26. Hanna N, Fidler IJ. Role of natural killer cells in the destruction of 20 circulating tumor emboli. J Natl Cancer Inst 1980;65:801-9.

21 27. Kaido T, Mori A, Oike F, Mizumoto M, Ogura Y, Hata K, et al. Impact 22 of pretransplant nutritional status in patients undergoing liver 
transplantation. Hepatogastroenterology 2010;57:1489-92.

28. Bassit RA, Sawada LA, Bacurau RF, Navarro F, Martins E Jr, Santos $\mathrm{RV}$, et al. Branched-chain amino acid supplementation and the immune response of long-distance athletes. Nutrition 2002;18:376-9.

29. García-de-Lorenzo A, Ortíz-Leyba C, Planas M, Montejo JC, Núñez R, Ordóñez FJ, et al. Parenteral administration of different amounts of branch-chain amino acids in septic patients: clinical and metabolic aspects. Crit Care Med 1997;25:418-24.

30. Kakazu E, Ueno Y, Kondo Y, Fukushima K, Shiina M, Inoue J, et al. Branched chain amino acids enhance the maturation and function of myeloid dendritic cells ex vivo in patients with advanced cirrhosis. Hepatology 2009;50:1936-45.

31. Laryea M, Watt KD, Molinari M, Walsh MJ, McAlister VC, Marotta PJ, et al. Metabolic syndrome in liver transplant recipients: prevalence and association with major vascular events. Liver Transpl 2007;13:1109-14.

32. Hanouneh IA, Feldstein AE, McCullough AJ, Miller C, Aucejo F, Yerian $\mathbf{L}$, et al. The significance of metabolic syndrome in the setting of recurrent hepatitis $\mathbf{C}$ after liver transplantation. Liver Transpl 2008;14:1287-93.

33. Anastácio LR, Ferreira LG, Ribeiro Hde S, Liboredo JC, Lima AS, Correia MI. Metabolic syndrome after liver transplantation: 
1 prevalence and predictive factors. Nutrition $2011 ; 27: 931-7$.

2 
1 Table 1. Univariate analysis of factors affecting posttransplant sepsis.

2

3 Table 2. Multivariate analysis of factors affecting posttransplant sepsis.

4

5 Table 3. Univariate analysis of factors affecting posttransplant bacteremia.

6

7 Table 4. Multivariate analysis of factors affecting posttransplant 8 bacteremia.

9

10 Table 5. Univariate analysis of factors affecting in-hospital death due to 11 infection.

12

13 Table 6. Multivariate analysis of factors affecting in-hospital death due to 14 infection. 
Table 1. Univariate analysis of factors affecting posttransplant sepsis

\begin{tabular}{llll} 
& Variable & Incidence of event & $P$ value \\
\hline Age $(y)$ & $<60(n=68)$ & $72 \%$ & 0.001 \\
Gender & $\geq 60(n=32)$ & $38 \%$ & \\
& Male $(n=46)$ & $52 \%$ & 0.051 \\
Original disease & Female $(n=54)$ & $70 \%$ & \\
& HCC $(n=34)$ & $50 \%$ & 0.460 \\
& HBV/HCV $(n=19)$ & $68 \%$ & \\
ABO blood type & PBC/PSC $(n=20)$ & $70 \%$ & \\
& FHF $(n=8)$ & $75 \%$ & \\
Cothers $(n=19)$ & $58 \%$ & 0.166 \\
Child-Pugh & Incompatible $(n=39)$ & $57 \%$ & \\
& A, B $(n=39)$ & $71 \%$ & 0.112 \\
MELD score & C $(n=61)$ & $51 \%$ & \\
& $<20(n=55)$ & $67 \%$ & \\
GRWR & $\geq 20(n=45)$ & $51 \%$ & 0.021 \\
& $<0.8 \%(n=28)$ & $73 \%$ & \\
& $\geq 0.8 \%(n=72)$ & $50 \%$ & 0.163 \\
& & $65 \%$ & \\
\hline
\end{tabular}




\begin{tabular}{|c|c|c|c|}
\hline \multirow[t]{2}{*}{ Graft } & Rt $(n=57)$ & $61 \%$ & 0.924 \\
\hline & Lt $(n=43)$ & $60 \%$ & \\
\hline \multirow[t]{2}{*}{ Operative time } & $<12 \mathrm{~h}(\mathrm{n}=25)$ & $68 \%$ & 0.403 \\
\hline & $\geq 12 h(n=75)$ & $59 \%$ & \\
\hline \multirow[t]{2}{*}{ Operative blood loss } & $<10 L(n=65)$ & $58 \%$ & 0.476 \\
\hline & $\geq 10 \mathrm{~L}$ ( $n=35$ ) & $66 \%$ & \\
\hline \multirow{2}{*}{$\begin{array}{l}\text { Preoperative BCM } \\
\text { No }\end{array}$} & Low $(n=24)$ & $83 \%$ & 0.002 \\
\hline & rmal or high $(n=64)$ & $48 \%$ & \\
\hline \multicolumn{3}{|c|}{$\begin{array}{l}\text { Preoperative BCAA enriched nutrient } \\
\text { mixture }\end{array}$} & 0.001 \\
\hline & With $(n=37)$ & $38 \%$ & \\
\hline & Absent $(n=63)$ & $73 \%$ & \\
\hline
\end{tabular}

HCC, hepatocellular carcinoma; HBV, hepatitis B virus; HCV, hepatitis C virus; PBC, primary biliary cirrhosis; PSC, primary sclerosing cirrhosis; FHF, fulminant hepatic failure; MELD, model for end-stage liver disease; GRWR, graft to recipient weight ratio; BCM, body cell mass; BCAA, branched-chain amino acids. 
Table 2. Multivariate analysis of factors affecting posttransplant sepsis

\begin{tabular}{cccc} 
Variable & Odds ratio & $95 \% \mathrm{Cl}$ & $P$ \\
\hline Preoperative low BCM & 4.633 & $1.493-17.701$ & 0.032 \\
$\begin{array}{c}\text { Absence of preoperative BCAA } \\
\text { enriched nutrient mixture }\end{array}$ & 3.201 & $1.202-7.849$ & 0.020 \\
\hline
\end{tabular}


Table 3. Univariate analysis of factors affecting posttransplant bacteremia

\begin{tabular}{llcc} 
& Variable & Incidence of event & $P$ value \\
\hline Age (y) & $<60(n=68)$ & $51 \%$ & 0.011 \\
& $\geq 60(n=32)$ & $25 \%$ & \\
Gender & Male $(n=46)$ & $39 \%$ & 0.470 \\
Original disease & Female $(n=54)$ & $46 \%$ & \\
& HCC $(n=34)$ & $41 \%$ & 0.880 \\
& HBV/HCV $(n=19)$ & $53 \%$ & \\
ABO blood type & PBC/PSC $(n=20)$ & $45 \%$ & \\
& FHF $(n=8)$ & $38 \%$ & \\
Compatible $(n=61)$ & $37 \%$ & 0.245 \\
Child-Pugh & Incompatible $(n=39)$ & $39 \%$ & \\
& A, B $(n=39)$ & $52 \%$ & 0.001 \\
MELD score & C $(n=61)$ & $23 \%$ & \\
& $<20(n=55)$ & $56 \%$ & \\
GRWR & $\geq 20(n=45)$ & $35 \%$ & 0.059 \\
& $<0.8 \%(n=28)$ & $53 \%$ & \\
& $\geq 0.8 \%(n=72)$ & $39 \%$ & 0.639 \\
& & $44 \%$ & \\
\hline
\end{tabular}




\begin{tabular}{|c|c|c|c|}
\hline \multirow[t]{2}{*}{ Graft } & Rt $(n=57)$ & $47 \%$ & 0.309 \\
\hline & Lt $(n=43)$ & $33 \%$ & \\
\hline \multirow[t]{2}{*}{ Operative time } & $<12 h(n=25)$ & $40 \%$ & 0.726 \\
\hline & $\geq 12 h(n=75)$ & $44 \%$ & \\
\hline \multirow[t]{2}{*}{ Operative blood loss } & $<10 L(n=65)$ & $34 \%$ & 0.012 \\
\hline & $\geq 10 \mathrm{~L}$ ( $n=35$ ) & $60 \%$ & \\
\hline \multirow{2}{*}{$\begin{array}{l}\text { Preoperative BCM } \\
\text { No }\end{array}$} & Low $(n=24)$ & $54 \%$ & 0.093 \\
\hline & rmal or high $(n=64)$ & $34 \%$ & \\
\hline \multicolumn{3}{|c|}{$\begin{array}{l}\text { Preoperative BCAA enriched nutrient } \\
\text { mixture }\end{array}$} & 0.015 \\
\hline & With $(n=37)$ & $26 \%$ & \\
\hline & Absent $(n=63)$ & $52 \%$ & \\
\hline
\end{tabular}

HCC, hepatocellular carcinoma; HBV, hepatitis B virus; HCV, hepatitis C virus; PBC, primary biliary cirrhosis; PSC, primary sclerosing cirrhosis; FHF, fulminant hepatic failure; MELD, model for end-stage liver disease; GRWR, graft to recipient weight ratio; BCM, body cell mass; BCAA, branched-chain amino acids. 
Table 4. Multivariate analysis of factors affecting posttransplant bacteremia

\begin{tabular}{cccc} 
Variable & Odds ratio & $95 \% \mathrm{Cl}$ & $P$ \\
\hline Child-Pugh C & 4.253 & $1.731-11.294$ & 0.001 \\
Operative blood loss $\geq 10 \mathrm{~L}$ & 2.983 & $1.229-7.541$ & 0.018 \\
\hline
\end{tabular}


Table 5. Univariate analysis of factors affecting in-hospital death due to infection

\begin{tabular}{llcc} 
& Variable & Incidence of event & $P$ value \\
\hline Age $(y)$ & $<60(n=68)$ & $19 \%$ & 0.017 \\
Gender & $\geq 60(n=32)$ & $3 \%$ & \\
Male $(n=46)$ & $17 \%$ & 0.369 \\
Original disease & Female $(n=54)$ & $11 \%$ & \\
& HCC $(n=34)$ & $6 \%$ & 0.462 \\
& HBV/HCV $(n=19)$ & $21 \%$ & \\
& PBC/PSC $(n=20)$ & $20 \%$ & \\
ABO blood type & FHF $(n=8)$ & $13 \%$ & \\
& Others $(n=19)$ & $16 \%$ & 0.684 \\
Child-Pugh & Incompatible $(n=61)$ & $13 \%$ & \\
& A, B $(n=39)$ & $16 \%$ & 0.030 \\
MELD score & C $(n=61)$ & $5 \%$ & \\
& $<20(n=55)$ & $20 \%$ & \\
GRWR & $\geq 20(n=45)$ & $9 \%$ & 0.118 \\
& $<0.8 \%(n=28)$ & $20 \%$ & \\
& $\geq 0.8 \%(n=72)$ & $7 \%$ & 0.192 \\
& & $17 \%$ & \\
\hline
\end{tabular}




\begin{tabular}{|c|c|c|c|}
\hline \multirow[t]{2}{*}{ Graft } & Rt $(n=57)$ & $16 \%$ & 0.550 \\
\hline & Lt $(n=43)$ & $12 \%$ & \\
\hline \multirow[t]{2}{*}{ Operative time } & $<12 \mathrm{~h}(\mathrm{n}=25)$ & $8 \%$ & 0.293 \\
\hline & $\geq 12 h(n=75)$ & $16 \%$ & \\
\hline \multirow[t]{2}{*}{ Operative blood loss } & $<10 L(n=65)$ & $11 \%$ & 0.213 \\
\hline & $\geq 10 \mathrm{~L}$ ( $n=35$ ) & $20 \%$ & \\
\hline \multirow{2}{*}{$\begin{array}{l}\text { Preoperative BCM } \\
\text { No }\end{array}$} & Low $(n=24)$ & $29 \%$ & 0.003 \\
\hline & rmal or high $(n=64)$ & $5 \%$ & \\
\hline \multicolumn{3}{|c|}{$\begin{array}{l}\text { Preoperative BCAA enriched nutrient } \\
\text { mixture }\end{array}$} & 0.884 \\
\hline & With $(n=37)$ & $14 \%$ & \\
\hline & Absent $(n=63)$ & $15 \%$ & \\
\hline
\end{tabular}

HCC, hepatocellular carcinoma; HBV, hepatitis B virus; HCV, hepatitis C virus; PBC, primary biliary cirrhosis; PSC, primary sclerosing cirrhosis; FHF, fulminant hepatic failure; MELD, model for end-stage liver disease; GRWR, graft to recipient weight ratio; BCM, body cell mass; BCAA, branched-chain amino acids. 
Table 6. Multivariate analysis of factors affecting in-hospital death due to infection

Variable

Variable
Preoperative low BCM

Odds ratio

$95 \% \mathrm{Cl}$

$P$ 